\title{
Structural Similarity in a Series of Alkali Metal Aluminates with Heteroleptic t-Butoxide - iso-Butyl Ligand Sets
}

\author{
[a] M. T. Whitelaw, A. R. Kennedy, R. E. Mulvey \\ WestCHEM, Department of Pure and Applied Chemistry \\ University of Strathclyde \\ 295 Cathedral Street \\ Glasgow G1 1XL \\ U.K. \\ E-mail: r.e.mulvey@strath.ac.uk
}

Michael T. Whitelaw, Alan R. Kennedy, and R. E. Mulvey*[a]

Supporting information for this article is given via a link at the end of the document

\begin{abstract}
With the aim of increasing the number of well-defined alkali metal aluminates, six new crystalline examples containing heteroleptic $t$-butoxide - $i$-butyl ligand sets are reported. NMR spectroscopic studies in $\mathrm{C}_{6} \mathrm{D}_{6}$ solution have determined their common general formula $\left[(i-\mathrm{Bu})_{2} \mathrm{Al}(\mathrm{OBu}-t)_{2} \mathrm{AM}\right.$. (D)], where $\mathrm{AM}=\mathrm{Li}, \mathrm{D}=2 \mathrm{THF}$, TMEDA or PMDETA; $A M=\mathrm{Na}, \mathrm{D}=\mathrm{TMEDA}$ or PMDETA; and $\mathrm{AM}=$ $\mathrm{K}, \mathrm{D}=\mathrm{PMDETA}$. X-ray crystallographic studies show that despite the different sized alkali metals involved all six complexes adopt a common dinuclear motif with [AIO(AM)O] ring cores. Though Al-OBu$t$-Li linkages are common, the heavier alkali metal examples reported here are exceptionally rare. These structures could be interpreted as co-complexes between monomeric forms of $t$-BuO(AM) and ( $i$ $\mathrm{Bu})_{2} \mathrm{Al}(\mathrm{OBu}-t)$. Discrete aluminium alkoxides are invariably oligomeric and attempts to make monomeric forms here with Al-OBu-t bonds failed, though success came with the aryloxide $\left[\mathrm{Al}(\operatorname{dipp})_{3}\right.$.THF] (dipp = 2,6-diisopropylphenoxide)
\end{abstract}

\section{Introduction}

Organoaluminium chemistry has long been studied in both academic and applied research, the fruits of which have resulted in important applications across different sectors of technology. ${ }^{1-}$ ${ }^{8}$ This is underscored by the fact that trimethylaluminium, $\mathrm{Me}_{3} \mathrm{Al}$, is the World record holder for the most common organometallic compound produced commercially in terms of tonnage. ${ }^{9}$ For example, trimethylaluminium finds use in producing methylaluminoxane (MAO), an important activator for ZieglerNatta catalysis, ${ }^{10}$ and in the synthesis of Tebbe's reagent; a mixed-metal compound for methylation of carbonyl compounds, ${ }^{11}$ and as an activator for an iron pre-catalyst in the oligomerisation of ethene. ${ }^{12}$ Aluminium's attributes, such as high natural abundance (the highest of any metal in the earth's crust), relatively low toxicity compared to that of precious metals, and inexpensive cost, ${ }^{13}$ have become even more appealing recently since there is a growing movement to develop more sustainable, more environmentally benign synthetic and catalytic processes. The development and fundamental study of well-defined organoaluminium compounds is therefore currently undergoing a resurgence..$^{8,14-20}$
Our specific interest in this resurgence overlaps with our general interest in synergistic alkali-metal-mediated synergistic effects in polar main group organometallic chemistry, the subject of a recent review article. ${ }^{21}$ This work has resulted in the synthesis of bimetallic lithium organoaluminate complexes that have found application as catalysts/co-catalysts in homogeneous catalytic hydroboration and hydrophosphination of unsaturated organic molecules (e.g., aldehydes, ketones, alkenes, alkynes). ${ }^{22-24}$ In stoichiometric synthesis we have shown that synergistic reactivity can even be achieved when the lithium and aluminium species are initially separated. This has been exploited in arene deprotonation reactions where the base LiTMP (TMP is 2,2,6,6tetramethylpiperidide) works effectively only when the trap $i$ $\mathrm{Bu}_{2} \mathrm{AlTMP}$ is introduced, in a tandem process referred to as "trans-metal-trapping" to distinguish it from the common practice of transmetallation. ${ }^{25-27}$

The primary aim of this present study was to add more stock to the library of well-defined bimetallic alkali metal aluminium compounds in a systematic manner, focusing on alkali metal aluminium co-complexes with heteroleptic $t$-butoxide - $i$-butyl ligand sets. Ligand choice was motivated by the commercial availability of tri-iso-butylaluminium $\left(i-\mathrm{Bu}_{3} \mathrm{Al}\right)$, one of the most widely used organoaluminium reagents in chemistry, and by the track record of the $t$-butoxide ligand in synergistic bimetallic chemistry, the best known example being the classic LochmannSchlosser superbase (LICKOR, commonly a mixture of $n$-BuLi and $t$-BuOK). ${ }^{28-32}$ Herein, we report the synthesis and characterisation of six such heteroleptic alkali metal aluminates. To our surprise, prior to this work there are no such aluminates having crystal structures containing (alkyl)Al-OBu-t-AM linkages, where $\mathrm{AM}$ is $\mathrm{Na}$ or $\mathrm{K}$, and only two examples when $\mathrm{AM}$ is $\mathrm{Li}$. A rare example of a monomeric aluminium aryloxide is also reported.

\section{Results and Discussion}

There are several reported methods for synthesising heterobimetallic aluminium alkoxides. These include reaction of pre-formed lithium aluminates with a parent alcohol, ${ }^{33}$ reaction of a pre-formed aluminium alkoxide with $n$-BuLi, ${ }^{34}$ lithiation of a parent alcohol and reaction of the generated lithium alkoxide in turn with either an alkyl aluminium or aluminium alkoxide 
reagent, ${ }^{35}$ or reaction of a parent alcohol with the base $\mathrm{LiAlH}_{4}{ }^{36}$ In 2002, Gordon and Watkin successfully synthesised two mixedmetal samarium-aluminium alkoxides on reacting $i-\mathrm{Bu}_{3} \mathrm{Al}$ with $\mathrm{Sm}(\mathrm{HMDS})_{3} \quad(\mathrm{HMDS}=1,1,1,3,3,3$-hexamethyldisilazide, $\left.\left[\mathrm{N}\left(\mathrm{SiMe}_{3}\right)_{2}\right]\right)$, followed by the addition of alcohol ( $i-\mathrm{PrOH}$ or $t-$ $\mathrm{BuOH}) .{ }^{37}$ Crystals obtained from these reactions showed the products to be mixed-metal dinuclear alkoxides with two alkoxide bridges (Scheme 1).
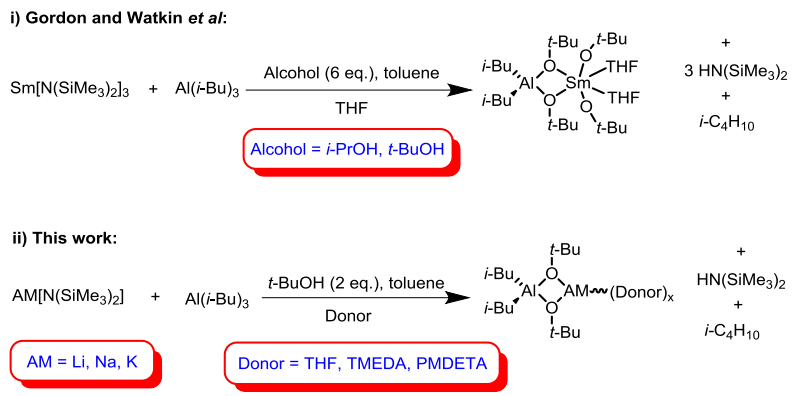

Scheme 1. Procedures carried out for i) the synthesis of various alkoxy-bridged samarium aluminates and ii) the synthesis of various tert-butoxy-bridged alkalimetal aluminates.

Significantly, in this method, two $i$-butyl groups remain attached to the f-block metal even under an excess of alcohol, so as our target was mixed $i$-butyl - $t$-butoxide complexes, we decided to use a modified version of the Gordon and Watkin method. Popular utility amide reagents, alkali metal (AM) HMDS compounds ( $\mathrm{AM}=\mathrm{Li}$, $\mathrm{Na}, \mathrm{K})^{38-44}$ replacing the lanthanide HMDS reagent were each mixed with $i-\mathrm{Bu}_{3} \mathrm{Al}$ and $t-\mathrm{BuOH}$ in a 1:1:2 stoichiometric ratio in toluene solution. Removal of the solvent in vacuo left a viscous oil residue, which was then suspended in hexane to which a stoichiometric quantity of a Lewis base donor ligand [THF, TMEDA (N,N,N'N'-tetramethylethylenediamine or PMDETA $(N, N, N, N$ "N"-pentamethyldiethylenetriamine)] was added. Crystals suitable for $\mathrm{X}$-ray crystallographic studies were obtained from six of these reactions producing $\left.\left[(i-\mathrm{Bu})_{2} \mathrm{Al}(\mathrm{OBu}-t)_{2} \mathrm{Li} \text {.(THF }\right)_{2}\right]$ 1, $\left[(i-\mathrm{Bu})_{2} \mathrm{Al}(\mathrm{OBu}-t)_{2} \mathrm{Li}\right.$. (TMEDA $\left.)\right] \quad$ 2, $\quad\left[(i-\mathrm{Bu})_{2} \mathrm{Al}(\mathrm{OBu}-\right.$ $t)_{2} \mathrm{Li}$.(PMDETA) $] \quad \mathbf{3}, \quad\left[(i-\mathrm{Bu})_{2} \mathrm{Al}(\mathrm{OBu}-t)_{2} \mathrm{Na}\right.$.(TMEDA $\left.)\right] \quad \mathbf{4}, \quad[(i-$ $\mathrm{Bu})_{2} \mathrm{Al}(\mathrm{OBu}-t)_{2} \mathrm{Na}$.(PMDETA $\left.)\right] 5$ and $\left[(i-\mathrm{Bu})_{2} \mathrm{Al}(\mathrm{OBu}-\right.$ $t)_{2} \mathrm{~K}$.(PMDETA)] 6. All air- and moisture-sensitive colourless crystals, these new compounds were isolated in yields of $74 \%$, $52 \%, 54 \% 32 \%, 48 \%$ and $34 \%$, respectively. Since the composition of each product $\mathbf{1}-\mathbf{6}$ matched the stoichiometry within the solution starting mixture, these reactions can be categorised as two-fold deprotonations, with AM(HMDS) deprotonating one alcohol molecule and one arm of $i-\mathrm{Bu}_{3} \mathrm{Al}$ deprotonating the other molecule (the latter in concurrence with the reactivity observed by Gordon and Watkin), producing the target alkali metal aluminium complex and a co-product of HMDS(H) or $i$-butane respectively. Determined by X-ray crystallographic studies, the molecular structures of all six compounds 1- $\mathbf{6}$ are shown together in Figure 1. Since all structures share related dinuclear motifs, selected analogous bond lengths and bond angles are compared in Tables 1 and 2, respectively.
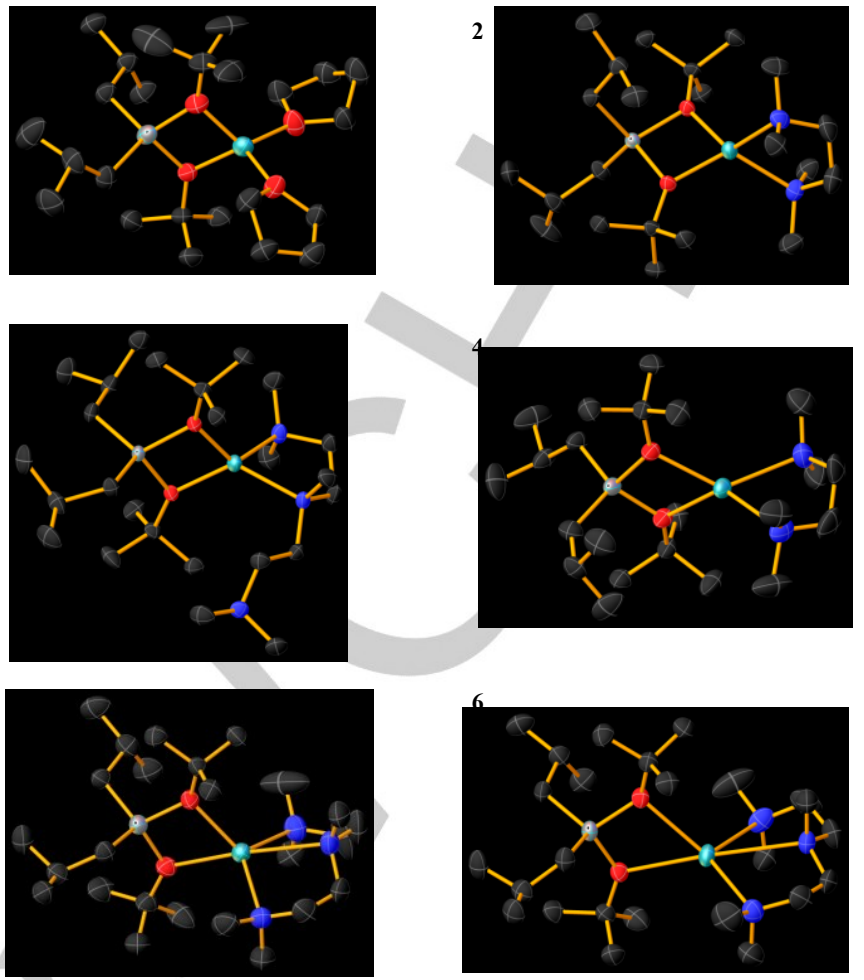

Figure 1. Molecular structures of (1) - (6) with key atom labelling. $\mathrm{H}$ atoms have been removed for clarity.

Table 1. Selected bond lengths $(\AA)$ of structures (1) - (6)

\begin{tabular}{|c|c|c|c|c|c|}
\hline$(1)^{[a],[d]}$ & $(2)^{[\mathrm{a}],[\mathrm{e}]}$ & $(3)^{[a],[f]}$ & $(4)^{[b], ~[e]}$ & $(5)^{[b],[f]}$ & $(6)^{[c],[f]}$ \\
\hline $\mathrm{Al} 1-\mathrm{C} 1$ & $1.991(2)$ & $1.9963(14)$ & $2.0027(17)$ & $1.9994(13)$ & $2.019(5)$ \\
\hline $\mathrm{Al} 1-\mathrm{C} 2$ & $2.022(15)$ & $1.9975(16)$ & 1.9951(17) & $1.9898(14)$ & $2.003(5)$ \\
\hline Al1 - O1 & $1.7943(15)$ & $1.8024(10)$ & $1.8037(11)$ & $1.7920(9)$ & $1.796(4)$ \\
\hline $\mathrm{Al} 1$ - O2 & $1.7953(18)$ & $1.7975(10)$ & $1.7970(11)$ & $1.7874(9)$ & $1.787(3)$ \\
\hline M1 - O1 & $1.931(4)$ & $1.976(3)$ & $1.958(3)$ & $2.2442(9)$ & $2.398(4)$ \\
\hline $\mathrm{M} 1-\mathrm{O} 2$ & $1.916(4)$ & $1.941(3)$ & $1.949(3)$ & $2.2384(9)$ & $2.293(4)$ \\
\hline M1 - D3 & $1.947(4)$ & $2.208(3)$ & $2.165(3)$ & $2.4455(12)$ & $2.550(5)$ \\
\hline M1 - D4 & $1.946(4)$ & $2.202(3)$ & $2.235(3)$ & $2.4499(13)$ & $2.781(4)$ \\
\hline M1 - D5 & - & - & - & - & $2.565(5)$ \\
\hline
\end{tabular}

[a] $\mathrm{M}=\mathrm{Li},[\mathrm{b}] \mathrm{M}=\mathrm{Na},[\mathrm{c}] \mathrm{M}=\mathrm{K},[\mathrm{d}] \mathrm{D}=\mathrm{THF}(\mathrm{O} 3, \mathrm{O} 4),[\mathrm{e}] \mathrm{D}=\mathrm{TMEDA}(\mathrm{N} 3, \mathrm{~N} 4)$, [f] D = PMDETA (N3, N4, N5)

Table 2. Selected bond angles $\left({ }^{\circ}\right)$ of structures (1) - (6).

\begin{tabular}{|c|c|c|c|c|c|}
\hline$(1)^{[\mathrm{a}],[\mathrm{d}]}$ & $(2)^{[a],[e]}$ & $(3)^{[a], f]}$ & $(4)^{[b],[e]}$ & $(5)^{[b], ~ f f]}$ & $(6)^{[c], ~ f f]}$ \\
\hline C1-Al1-C2 & $110.5(4)$ & $117.09(7)$ & $116.12(7)$ & $117.16(6)$ & $114.0(2)$ \\
\hline C1-Al1-O1 & $115.22(8)$ & $109.41(5)$ & $112.73(6)$ & $109.63(5)$ & $112.1(2)$ \\
\hline C1-Al1-O2 & $112.45(9)$ & $113.08(6)$ & $108.91(6)$ & $113.32(5)$ & $108.10(18)$ \\
\hline C2-Al1-O1 & $106.7(4)$ & $110.02(6)$ & $110.53(6)$ & $108.31(5)$ & $115.5(2)$ \\
\hline C2-Al1-O2 & $120.6(3)$ & $112.98(6)$ & $114.98(6)$ & $111.78(5)$ & $110.59(19)$ \\
\hline
\end{tabular}




\begin{tabular}{|c|c|c|c|c|c|}
\hline O1-Al1-O2 & $89.85(7)$ & $91.16(5)$ & $90.93(5)$ & $94.05(4)$ & $94.73(16)$ \\
\hline Al1-O1-M1 & $93.22(12)$ & $92.61(8)$ & $93.19(9)$ & $96.83(4)$ & $95.79(15)$ \\
\hline Al1-O2-M1 & $93.68(13)$ & $93.93(8)$ & $93.70(9)$ & $97.18(4)$ & $99.78(15)$ \\
\hline O1-M1-O2 & $82.44(16)$ & $82.07(10)$ & $82.16(11)$ & $71.50(3)$ & $68.34(12)$ \\
\hline O1-M1-D3 & $116.7(2)$ & $121.40(12)$ & $120.99(15)$ & $129.52(4)$ & $107.60(15)$ \\
\hline O1-M1-D4 & 117.11(19) & $126.41(13)$ & $127.11(14)$ & $131.93(4)$ & $175.52(16)$ \\
\hline O1-M1-D5 & - & - & - & - & $110.80(15)$ \\
\hline O2-M1-D3 & $120.0(2)$ & $127.20(13)$ & $123.15(14)$ & $130.30(4)$ & $117.74(15)$ \\
\hline O2-M1-D4 & $114.71(19)$ & $121.52(13)$ & $124.13(14)$ & $127.86(5)$ & $115.95(15)$ \\
\hline O2-M1-D5 & - & - & - & - & $117.01(16)$ \\
\hline D3-M1-D4 & $105.32(18)$ & $84.02(10)$ & $84.67(11)$ & $75.55(5)$ & $69.57(15)$ \\
\hline D3-M1-D5 & - & - & - & - & $121.24(17)$ \\
\hline D4-M1-D5 & - & - & - & - & $68.84(16)$ \\
\hline
\end{tabular}

[a] $\mathrm{M}=\mathrm{Li},[\mathrm{b}] \mathrm{M}=\mathrm{Na},[\mathrm{c}] \mathrm{M}=\mathrm{K},[\mathrm{d}] \mathrm{D}=\operatorname{THF}(\mathrm{O} 3, \mathrm{O} 4),[\mathrm{e}] \mathrm{D}=\operatorname{TMEDA}(\mathrm{N} 3, \mathrm{~N} 4)$, [f] D = PMDETA (N3, N4, N5)

The lithium structures (1) - (3) display essentially planar fourmembered (AIOLiO) rings with $t$-butoxide bridges. Each metal centre occupies a distorted tetrahedral site with two terminal $i$-Bu ligands completing the Al coordination and two donor atoms (from two THF ligands, one TMEDA ligand and one PMDETA ligand in $\mathbf{1}, \mathbf{2}$, and $\mathbf{3}$ respectively) completing the $\mathrm{Li}$ coordination. The bidentate coordination of $\mathrm{Li}$ by trifunctional PMDETA is unusual though there are some precedents for it ${ }^{27,45-48}$ in the Cambridge Structural Database (CSD). ${ }^{49}$ The first sodium structure $\mathbf{4}$ closely resembles that of $\mathbf{2}$, while the second sodium structure $\mathbf{5}$ also has a $(\mathrm{AIONaO})$ ring as in $\mathbf{4}$, but in contrast to the lithium congener $\mathbf{3}$ the PMDETA here uses its full complement of nitrogen donor atoms, making the sodium atom penta-coordinate. Disorder in the structure of $\mathbf{5}$ rules out an analysis of its dimensions, though its connectivity is unequivocal. Moving to potassium in $\mathbf{6}$, the fourmembered (AIOKO) ring deviates from planarity though the deviation is small (sum of endocyclic bond angles, $356.93^{\circ}$ ), but as in 5 PMDETA maintains its tridentate coordination to this larger alkali metal meaning it also takes up a distorted trigonal bipyramidal geometry in its penta-coordinate state. Atoms $\mathrm{O} 1$ and N4 occupy the axial positions [bond angle of $172.05(5)^{\circ}$ ] and $\mathrm{O} 2$, N3 and N5 occupy the equatorial positions [bond angles of $118.68(6)^{\circ}, 112.20(6)^{\circ}$ and $\left.119.09(6)^{\circ}\right]$. This strong structural resemblance between the lithium, sodium and potassium complexes is unusual in homometallic chemistry with the heavier alkali metals often preferring higher states of association (frequently polymeric) than their lighter congener due to their greater availability of coordination space. ${ }^{50-52}$ The fact that such similarity is present in these heterobimetallic structures can be attributed to the greater Lewis acidity of aluminium, which dictates the primary architecture of the structures, the tetrahedral ate arrangement, leaving the alkali metals to fulfil their coordination requirement through secondary interactions with the phenoxide bridges and donor solvents.
Inspecting the dimensions of the new structures, the terminal Al$\mathrm{C}(i-\mathrm{Bu})$ bonds show little variation across all six structures spanning the narrow range $[1.9898(14)-2.022(15) \AA]$. Similarly, the bridging $\mathrm{Al}-\mathrm{O}$ bonds are nearly all the same length [range: $1.7821(16)-1.8037(11) \AA]$. This pattern is consistent with the stronger Lewis acidity of the trivalent Al centre, pulling the ligands to their preferred bonding length irrespective of which alkali metal is partnering them. As expected, the AM-O bridge lengths reflect the size of the alkali metal. The Li-O bond lengths [range: 1.916(4) $-1.976(3) \AA]$ ] are influenced by the Lewis base donor strength, with the weakest donor THF in 1 leading to the shortest $\mathrm{Li}-\mathrm{O}$ bridge lengths (average: $1.923 \AA$ ), while those involving the bidentate and pseudo-bidentate nitrogen donor ligands have near identical average lengths [1.958 $\AA$ and $1.953 \AA$ for $\mathbf{2}$ and $\mathbf{3}$, respectively]. Interestingly, the space around the Li centre is more cramped with bidentate TMEDA, leading to more asymmetry in the Li-O bridge bonds in 2 ( $\triangle \mathrm{Li}-\mathrm{O}$ bond lengths, $0.035 \AA$; cf., 0.009 $\AA$ for 3 ). Coordination number differences account for the shorter $\mathrm{Na}-\mathrm{O}$ bonds in $\mathbf{4}$ compared to those in $\mathbf{5}$. The four-coordinate $\mathrm{Na}$ in 4 has an average $\mathrm{Na}-\mathrm{O}$ bond length of $2.241 \AA$, whereas with the five-coordinate $\mathrm{Na}$ in $\mathbf{5}$ it increases to $2.345 \AA$. The potassium aluminate $\mathbf{6}$ adopts the same basic architecture as $\mathbf{5}$, though the presence of the heavier alkali metal extends the average M-O bond length to $2.637 \AA$. This is a factor in the irregularity of the aforementioned four-membered (AIOMO) rings getting more pronounced with the increasing size of the alkali metal, as reflected in the decreasing trend observed in the OMO bridge angle $\left[82.44(16)^{\circ}, \quad 82.07(10)^{\circ}, 82.16(11)^{\circ}, \quad 71.50(3)^{\circ}\right.$, and $60.21(5)^{\circ}$ for 1-6 (omitting 5), respectively].

${ }^{1} \mathrm{H}$ and ${ }^{13} \mathrm{C}$ NMR spectroscopic data were collected in $\mathrm{C}_{6} \mathrm{D}_{6}$ solution for each complex (1) - (6). The ${ }^{1} \mathrm{H}$ spectra of the lithium aluminate complexes (1) - (3) showed characteristic $i$-butyl resonances comprising a nonet, a doublet and a second doublet at approximately $2.35,1.41$, and $0.38 \mathrm{ppm}$, respectively, with the third resonance associated with the most electronegative $\mathrm{CH}_{2}$ group directly attached to the Al centre. The chemical shifts of these resonances do not move significantly in the sodium aluminates $\mathbf{4}$ and $\mathbf{5}$ (approximately at 2.38, 1.44 and $0.35 \mathrm{ppm}$ ) or the potassium aluminate $6(2.43,1.43$ and $0.38 \mathrm{ppm})$. Consistent with the single OBu- $t$ environment in the crystal structures, a sharp singlet is found at $1.38 \mathrm{ppm}$ (approximately) for $\mathbf{1}-\mathbf{3}, 1.44$ ppm (approximately) for $\mathbf{4}$ and $\mathbf{5}$, and $1.45 \mathrm{ppm}$ for $\mathbf{6}$, corresponding to the equivalent $\mathrm{CH}_{3}$ arms of the OBu- $t$ group. The different donor ligands in $\mathbf{1}-\mathbf{6}$ all show their expected ${ }^{1} \mathrm{H}$ NMR resonances. Complexes (1), (2), and (4) all show six distinct environments in the ${ }^{13} \mathrm{C}$ NMR spectra, while complexes (3), (5), and (6) all show eight distinct environments. This is one less than would be expected for each structure (except for 3 ) as the quadrupolar $\mathrm{Al}$ nucleus can broaden the signals of directly attached groups, here the iso-butyl $\mathrm{CH}_{2}$, often making them not observable. This was proven through HSQC analysis (see Supporting Information). In the case of $\mathbf{3}$, the asymmetrical nature of the PMDETA ligand is not observable under the conditions studied leading to fewer resonances than expected, suggesting that the ligating nitrogen atoms are interchanging and making both terminal $\mathrm{Me}_{2} \mathrm{~N}$ units appear equivalent on this timescale. Clearly, on the basis of these data, the identity of the alkali metal exerts little influence on the electronic nature of the contents of the anionic aluminium coordination sphere as expected from the similarities of the crystal structures. Complexes (1) - (3) show one 
sharp resonance in the ${ }^{7} \mathrm{Li}$ NMR spectra at approximately 0.10 , 0.25 and $-0.23 \mathrm{ppm}$, respectively. Fully assigned NMR spectroscopic data can be found in the Experimental Section.

One could view the molecular structures of (1) - (6) superficially and dismiss them as simple expected hetero-dinuclear arrangements. However, it is interesting to ponder that they could also be interpreted as a contacted ion-pair, co-complexes between monomeric forms of $(i-\mathrm{Bu})_{2} \mathrm{Al}(\mathrm{OBu}-t)$ and $t-\mathrm{BuO}(\mathrm{AM}){ }^{53}$, ${ }^{54}$ These reactions could have alternatively produced a separated mixture of these two components, but in all cases cocomplexation is preferred, no doubt supported by the additional presence of the donor ligands that complete the coordination of the alkali metals. Steric factors must also play a role given the large sizes of the $i-\mathrm{Bu}$ and $t$-BuO ligands as a dimeric $[(i-$ $\left.\mathrm{Bu})_{2} \mathrm{Al}(\mathrm{OBu}-t)\right]_{2}$ structure would be more sterically crowded than the mixed-metal structures. Though $t$-BuOLi can be considered a pseudo-halide, the steric bulk and stereochemistry of its anionic moiety precludes it from forming a salt-like lattice structure like that of $\mathrm{LiCl}$. Parent, unsolvated $t$-BuOLi displays an interesting structural diversity in the crystalline state from a hexameric ${ }^{55}$ to an octameric aggregate. ${ }^{56}$ This propensity to form molecular structures linked to its good solubility in organic solvents makes $t$ BuOLi an excellent co-complexing agent ${ }^{57-62}$ as evidenced most importantly in the aforementioned Lochmann-Schlosser superbase,$^{32}$ though in that composition it is generated in situ from $n$-BuLi and $t$-BuOK and exists in a co-complexed form. Though having longer and weaker AM-O bonds than in $t-B u O L i$, both $t$ BuONa in 4 and 5 and $t$-BuOK in 6 also co-complex with monomeric $(i-\mathrm{Bu})_{2} \mathrm{Al}(\mathrm{OBu}-t)$ showing that these heavier alkali metals retain oxophilic character. Searching the Cambridge Structural Database (CSD) for complexes containing an Al-OBu$t-\mathrm{Li}$ fragment reveals 26 hits, ${ }^{63-69}$ which reduces to one result with potassium and none at all with sodium, hence demonstrating the relative rarity of the heavier alkali metal structures reported here. Of the lithium examples, only one, the tris-alkoxide [(OBu$t)\left[\left(\mathrm{Me}_{3} \mathrm{Si}\right)_{3} \mathrm{C}\right] \mathrm{Al}(\mathrm{OBu}-t)_{2} \mathrm{Li}$.(THF)] has a similar dinuclear motif to that found here though it displays mono THF solvation in contrast to the di THF solvation of $1 .^{64}$ The one potassium example $\left[\mathrm{Al}_{6} \mathrm{~K}_{8}\left\{\mathrm{Al}(\mathrm{OBu}-t)_{3}\right\}_{6}\right]$ bears no resemblance to the structure of $\mathbf{6}$, being a low valent aluminium alkoxide displaying a hybrid structure between a metalloid cluster and a hypothetical molecular Zintl phase. ${ }^{70}$ Note that low valent aluminium chemistry is an area currently attracting increasing interest. ${ }^{16,71-73}$

The structures of (1) - (6) reaffirm the strong oxophilic character of $\mathrm{Al}(\mathrm{III})$. It is interesting to note that the co-complexation with the alkali metal witnessed here realises monomeric organoaluminium alkoxide fragments, albeit contained within a heterodinuclear arrangement. Most parent organoaluminium alkoxide species are oligomeric due to the strong oxophilic character of the metal and the bridging propensity of alkoxide ligands. These oligomeric species are widely known and documented throughout the literature; indeed a search for the $\mathrm{Al}(\mu-\mathrm{O})_{2} \mathrm{Al}$ unit on the CSD revealed 860 hits, emphasising how aluminium oxide containing compounds commonly form oligomeric species. A germane example is the tris-alkoxide $(\mathrm{OBu}-t)_{2} \mathrm{Al}(\mu-\mathrm{OBu}-t)_{2} \mathrm{Al}(\mathrm{OBu}-t)_{2},{ }^{74}$ which is dimeric. As a side issue to our main focus on ate compounds, we also tried to synthesise monomeric variants of this tris-alkoxide using the Lewis base donor ligands THF,
TMEDA and PMDETA, along with attempting co-complexation with the aforementioned LiTMP at reflux temperature. However, all of these attempts proved fruitless leading always to recrystallisation of the dimer. In order to prevent this oligomerisation, we switched to an aryl alcohol to increase the steric bulk around the metal centre. Thus, reaction of 2,6diisopropylphenol (dippH) with $\mathrm{Me}_{3} \mathrm{Al}$ in hexane at room temperature resulted in the visible effervescence of gas and the formation of a dark green solution. THF was added before the solvent was removed in vacuo, and the solid residue was recrystallised from a hexane/toluene mixture to form colourless block crystals in a $62 \%$ isolated yield. X-ray crystallographic studies revealed these crystals to be the desired monomeric aryloxide $\left[\mathrm{Al}(\mathrm{dipp})_{3} . \mathrm{THF}\right](7)$, the structure of which is shown in Figure 2 with key dimensions in Table 3.

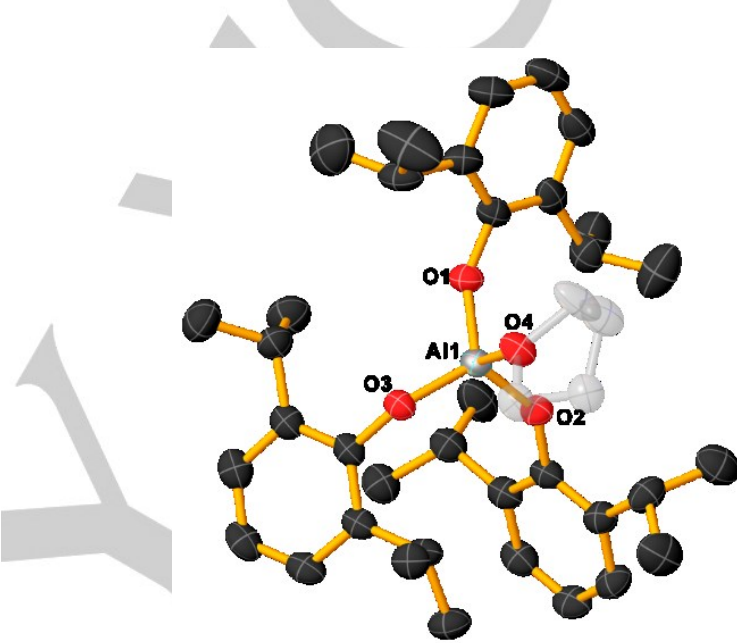

Figure 2. Molecular structure of (7) with key atoms labelled. $\mathrm{H}$ atoms have been removed for clarity. The THF molecule has been set to $40 \%$ transparency for clarity.

Table 3. Selected bond lengths $(\AA)$ and angles $\left({ }^{\circ}\right)$ of $(7)$.

\begin{tabular}{lcll}
\hline Al1-O1 & $1.712(2)$ & O1-Al1-O2 & $112.54(10)$ \\
Al1-O2 & $1.709(2)$ & O1-Al1-O3 & $115.74(11)$ \\
Al1-O3 & $1.7127(19)$ & O1-Al1-O4 & $103.37(10)$ \\
Al1-O4 & $1.865(2)$ & O2-Al1-O3 & $116.91(10)$ \\
& & O2-Al1-O4 & $105.33(11)$ \\
& & O3-Al1-O4 & $100.47(10)$
\end{tabular}

Predictably, the solitary Al centre sits in a distorted tetrahedral geometry comprising 4 oxygen centres with a mean O-Al-O bond angle of $109.06^{\circ}$. The $\mathrm{Al}-\mathrm{O}(\mathrm{aryl})$ bond lengths (mean length, $1.7112 \AA)$ are slightly shorter than the Al-OBu-t bonds in aluminates (1) - (6) $(1.793 \AA)$, with the dative bond to the solvating THF being expectedly significantly longer $[1.865(2) \AA]$. It is worth noting that Barron et al. have previously synthesised a number of aluminium aryloxide compounds, including the pyridine-solvate of $7 .{ }^{75}$ This pyridine solvate has a mean Al$\mathrm{O}($ aryl) bond length of $1.705 \AA$, the shortness of which was attributed to $\pi$-bonding between the oxygen lone pairs and the Al$\mathrm{O} \pi^{*}$ orbital on the four-coordinate aluminium centre. Given the similarity in length with that of 7 (mean length, $1.7112 \AA$ ), it can be assumed that such $\pi$-bonding also resides in 7 . 


\section{Conclusion}

This study has added several new well-defined alkali metal organoaluminium alkoxide co-complexes to the library of such compounds, the most significantly being, to the best of our knowledge, the first crystallographically characterised heavier alkali metal examples containing (alkyl)Al-OBu-t-AM linkages, where $\mathrm{AM}$ is $\mathrm{Na}$ or $\mathrm{K}$. Learning more about how alkali metal complexes and organoaluminium compounds co-complex and the structures that such co-complexes adopt will help the rational development of new chemistry in areas such as homogeneous catalysis. We recently demonstrated this idea with the report of the lithium phosphidoaluminate $i-\mathrm{Bu}_{3} \mathrm{AIPPh}_{2} \mathrm{Li}(\mathrm{THF})_{3}$ that functions as a catalyst for the hydrophosphination of alkynes, alkenes, and carbodiimides. ${ }^{24}$ In this catalyst the Li and Al centres are connected by a $\mathrm{P}$ bridge.

\section{Experimental Section}

General procedure: All reactions and manipulations were performed under a protective argon atmosphere using standard glovebox techniques, or under a protective nitrogen atmosphere using standard Schlenk techniques. Hexane, THF and toluene were dried by heating to reflux over sodium benzophenone ketyl and then distilled under nitrogen prior to use. $\mathrm{C}_{6} \mathrm{D}_{6}$ was degassed by freeze-pump-thaw methods and stored over activated $4 \AA$ molecular sieves. All reagents were purchased from commercial sources and used as received, unless states otherwise. TMEDA, PMDETA and HMDS(H) were distilled and stored over activated $4 \AA$ molecular sieves prior to use. NMR spectra were recorded on a Bruker AV3 or AV $400 \mathrm{MHz}$ spectrometer operating at $400.13 \mathrm{MHz}$ for ${ }^{1} \mathrm{H}, 155.47$ $\mathrm{MHz}$ for ${ }^{7} \mathrm{Li}$ and $100.62 \mathrm{MHz}$ for ${ }^{13} \mathrm{C}$. All ${ }^{13} \mathrm{C}$ spectra were proton decoupled. ${ }^{1} \mathrm{H},{ }^{13} \mathrm{C}\left\{{ }^{1} \mathrm{H}\right\}$ and ${ }^{7} \mathrm{Li}$ chemical shifts are expressed in parts per million $(\delta$, ppm) and referenced to residual solvent peaks. HSQC measurements were recorded on an AV $400 \mathrm{MHz}$ spectrometer operating at $400.13 \mathrm{MHz}$, using the pulse program hsqcedetgp. Data for compounds (1) - (7) were collected on an Oxford Diffraction Gemini $S$ instrument with graphitemonochromated $\mathrm{Cu} \mathrm{Ka}(\lambda 1.54184 \AA)$ radiation. Data collection and processing used CrysalisPro software. ${ }^{76}$ All structures were solved and refined to convergence against $\mathrm{F}^{2}$ for all independent reflections by the fullmatrix least squares method using SHELXL-2014 implemented within WINGX. ${ }^{77,78}$ All non-hydrogen atoms were refined using anisotropic thermal parameters. Structure $\mathbf{5}$ was identified as a twinned sample post data collection. The program ROTAX was used to generate a hklf5 formatted reflection file. ${ }^{79}$ Refinement using this file and as a two component twin gave a superior model with BASF $=0.2398(33)$. Several of the structures contained disordered fragments. All of these were modelled with atoms split over two sites and with appropriate restraints and constraints applied to ensure normal geometries and displacement behaviours. Treated in such a way were; two butyl and two THF ligands of 1, a butyl ligand and the TMEDA ligand of 4, the ligands of one of the two crystallographically unique complexes of $\mathbf{5}$ and, two of the butyl groups of 6. Selected crystallographic data are shown in Tables S1, S2 and S3 and full details in cif format are available from CCDC (1999145 - 1999151).

Synthesis of LiHMDS: 80 To a solution of HMDS(H) $(1.04 \mathrm{ml} ; 5 \mathrm{mmol})$ in hexane $(10 \mathrm{ml})$ was added $\mathrm{nBuLi}(1.6 \mathrm{M} /$ hexane; $3.125 \mathrm{ml} ; 5 \mathrm{mmol})$. The transparent, colourless solution was stirred at room temperature overnight before the solvent was removed in vacuo, leaving a white solid material which was then isolated $(0.831 \mathrm{~g} ; 4.98 \mathrm{mmol}$; $99.5 \%$ yield $) .{ }^{1} \mathrm{H}$ NMR $(400.1$ $\left.\mathrm{MHz}, \mathrm{C}_{6} \mathrm{D}_{6}, 300 \mathrm{~K}\right)$ : $\delta 0.126\left(\mathrm{~s}, 18 \mathrm{H}, \mathrm{CH}_{3}\right) \mathrm{ppm}$. ${ }^{7} \mathrm{Li} \mathrm{NMR}(155.47 \mathrm{MHz}$, $\left.\mathrm{C}_{6} \mathrm{D}_{6}, 300 \mathrm{~K}\right): \delta 1.121$ (s) ppm.

Synthesis of $\left.\left[(\mathrm{i}-\mathrm{Bu})_{2} \mathrm{Al}(\mathrm{OBu}-\mathrm{t})_{2} \mathrm{Li} \text {.(THF }\right)_{2}\right]$, 1: To a solution of LiHMDS $(0.1336 \mathrm{~g} ; 0.8 \mathrm{mmol})$ in toluene $(5 \mathrm{ml})$ was added $\mathrm{Al}(\mathrm{i}-\mathrm{Bu})_{3}(1 \mathrm{M} / \mathrm{hexane}$; $0.8 \mathrm{ml} ; 0.8 \mathrm{mmol}$ ) and this was stirred at room temperature for 1 hour. To this transparent, colourless solution was added t-BuOH $(0.15 \mathrm{ml} ; 1.6$ $\mathrm{mmol}$ ) and this was stirred at room temperature overnight. After this, all of the solvent was removed in vacuo, leaving behind a colourless but viscous oil residue; this was resuspended in hexane $(2 \mathrm{ml})$ and THF was added to the white suspension $(0.48 \mathrm{ml} ; 2.5 \mathrm{mmol})$. This was stored at $-30^{\circ} \mathrm{C}$ and a crop of colourless block crystals were obtained after several hours. These were isolated by filtration $(0.245 \mathrm{~g} ; 0.592 \mathrm{mmol} ; 74 \%$ yield $) .{ }^{1} \mathrm{H}$ NMR (400.1 MHz, $\mathrm{C}_{6} \mathrm{D}_{6}, 300 \mathrm{~K}$ ): $\delta 0.382$ (d, J = $6.94 \mathrm{~Hz}, 4 \mathrm{H}, \mathrm{CH}_{2}$ of $\mathrm{i}-\mathrm{Bu}$ ); 1.326 (m, J = 3.32 Hz, 8H, CH ${ }_{2}$ of THF); 1.382 (s, 18H, $\mathrm{CH}_{3}$ of t-BuO); 1.418 (d, $\mathrm{J}=6.52 \mathrm{~Hz}, 12 \mathrm{H}, \mathrm{CH}_{3}$ of $\mathrm{i}-\mathrm{Bu}$ ); 2.358 (nonet, $\mathrm{J}=6.60 \mathrm{~Hz}, 2 \mathrm{H}, \mathrm{CH}$ of $\mathrm{i}-\mathrm{Bu}$ ); $3.478\left(\mathrm{~m}, \mathrm{~J}=6.58,8 \mathrm{H}, \mathrm{CH}_{2}\right.$ of THF) ppm. ${ }^{13} \mathrm{C}\left\{{ }^{1} \mathrm{H}\right\} \mathrm{NMR}\left(100.6 \mathrm{MHz}, \mathrm{C}_{6} \mathrm{D}_{6}\right.$, 300K): $\delta 24.99$ (s, $\mathrm{CH}_{2}$ of THF); 27.18 (s, CH of i-Bu); 29.27 (s, $\mathrm{CH}_{3}$ of i$\mathrm{Bu}$ ); 33.48 (s, $\mathrm{CH}_{3}$ of t-BuO); 67.10 (s, C of t-BuO); 68.00 (s, $\mathrm{CH}_{2}$ of THF) ppm. ${ }^{7}$ Li NMR (155.5 MHz, $\left.\mathrm{C}_{6} \mathrm{D}_{6}, 300 \mathrm{~K}\right): \delta-0.102$ (s) ppm.

Synthesis of $\left[(\mathrm{i}-\mathrm{Bu})_{2} \mathrm{Al}(\mathrm{OBu}-\mathrm{t})_{2} \mathrm{Li}\right.$.TMEDA], 2: To a solution of LiHMDS $(0.167 \mathrm{~g} ; 1 \mathrm{mmol})$ in toluene $(5 \mathrm{ml})$ was added $\mathrm{Al}(\mathrm{i}-\mathrm{Bu})_{3}(1 \mathrm{M} /$ hexane; $1 \mathrm{ml}$; $1 \mathrm{mmol}$ ) and this was allowed to stir at room temperature for 1 hour. After this, t-BuOH was added $(0.1875 \mathrm{ml} ; 2 \mathrm{mmol})$ and this transparent, colourless solution was stirred at room temperature overnight. After this, all of the solvent was removed in vacuo, leaving behind a colourless but viscous oil residue; this was resuspended in hexane $(2 \mathrm{ml})$ and TMEDA was added to the white suspension $(0.23 \mathrm{ml} ; 1.5 \mathrm{mmol})$. This was stored at $-30{ }^{\circ} \mathrm{C}$ and a crop of colourless block crystals were obtained after several hours. These were isolated by filtration $(0.213 \mathrm{~g} ; 0.52 \mathrm{mmol} ; 52 \%$ yield). ${ }^{1} \mathrm{H}$ NMR (400.1 MHz, C6 6 , $300 \mathrm{~K}$ ): $\delta 0.387$ (d, J = 6.96 Hz, 4H, $\mathrm{CH}_{2}$ of i-Bu); 1.386 (s, $18 \mathrm{H}, \mathrm{CH}_{3}$ of t-BuO); 1.411 (d, J = 6.55 Hz, $12 \mathrm{H}, \mathrm{CH}_{3}$ of $\mathrm{i}-\mathrm{Bu}$ ); 1.660 (s, $4 \mathrm{H}, \mathrm{CH}_{2}$ of TMEDA); 1.897 (s, 12H, $\mathrm{CH}_{3}$ of TMEDA); 2.334 (nonet, $\mathrm{J}=6.56 \mathrm{~Hz}, 2 \mathrm{H}, \mathrm{CH}$ of i-Bu) ppm. ${ }^{13} \mathrm{C}\left\{{ }^{1} \mathrm{H}\right\} \mathrm{NMR}\left(100.6 \mathrm{MHz}, \mathrm{C}_{6} \mathrm{D}_{6}\right.$, $300 \mathrm{~K}$ ): $\delta 26.68$ (s, $\mathrm{CH}$ of i-Bu); 28.79 (s, $\mathrm{CH}_{3}$ of i-Bu); 33.38 (s, $\mathrm{CH}_{3}$ of t$\mathrm{BuO}$ ); 46.13 (s, $\mathrm{CH}_{3}$ of TMEDA); 56.32 (s, $\mathrm{CH}_{2}$ of TMEDA); 66.80 (s, C of t-BuO) ppm. ${ }^{7} \mathrm{Li} \mathrm{NMR}\left(155.5 \mathrm{MHz}, \mathrm{C}_{6} \mathrm{D}_{6}, 300 \mathrm{~K}\right.$ ): $\delta-0.256$ (s) ppm.

Synthesis of [(i-Bu $)_{2} \mathrm{Al}(\mathrm{Obu}-\mathrm{t})_{2} \mathrm{Li}$.PMDETA], 3: To a solution of LiHMDS $(0.167 \mathrm{~g} ; 1 \mathrm{mmol})$ in toluene $(5 \mathrm{ml})$ was added $\mathrm{Al}(\mathrm{iBu})_{3}(1 \mathrm{M} /$ hexane; $1 \mathrm{ml}$; $1 \mathrm{mmol})$ and this was stirred at room temperature for 1 hour. To this, t$\mathrm{BuOH}(0.1875 \mathrm{ml} ; 2 \mathrm{mmol})$ was added and this transparent, colourless solution was allowed to stir at room temperature overnight. After this, all of the solvent was removed in vacuo leaving a colourless but viscous oil. This was resuspended in hexane $(2 \mathrm{ml})$ before PMDETA was added to the white suspension $(0.31 \mathrm{ml} ; 1.5 \mathrm{mmol})$; the transparent solution was stored at $-30{ }^{\circ} \mathrm{C}$ and a crop of colourless block crystals were present after several hours and were isolated by filtration $\left(0.254 \mathrm{~g} ; 0.54 \mathrm{mmol} ; 54 \%\right.$ yield). ${ }^{1} \mathrm{H}$ $\operatorname{NMR}\left(400.1 \mathrm{MHz}, \mathrm{C}_{6} \mathrm{D}_{6}, 300 \mathrm{~K}\right)$ : $\delta 0.377$ (d, J = 6.90 Hz, 4H, $\mathrm{CH}_{2}$ of i-Bu); $1.400\left(\mathrm{~d}, \mathrm{~J}=6.61 \mathrm{~Hz}, 12 \mathrm{H}, \mathrm{CH}_{3}\right.$ of $\left.\mathrm{i}-\mathrm{Bu}\right) ; 1.415$ (s, $18 \mathrm{H}, \mathrm{CH}_{3}$ of t-BuO); 2.018 (s, 3H, $\mathrm{CH}_{3}$ of PMDETA); 2.044 (s, 12H, $\mathrm{CH}_{3}$ of PMDETA); 2.101 (t, $\mathrm{J}=5.55 \mathrm{~Hz}, 4 \mathrm{H}, \mathrm{CH}_{2}$ of PMDETA); $2.174\left(\mathrm{t}, \mathrm{J}=5.67 \mathrm{~Hz}, 4 \mathrm{H}, \mathrm{CH}_{2}\right.$ of PMDETA); 2.332 (nonet, $\mathrm{J}=6.53 \mathrm{~Hz}, 2 \mathrm{H}, \mathrm{CH}$ of i-Bu) ppm. ${ }^{13} \mathrm{C}\left\{{ }^{1} \mathrm{H}\right\} \mathrm{NMR}$ $\left(100.6 \mathrm{MHz}, \mathrm{C}_{6} \mathrm{D}_{6}, 300 \mathrm{~K}\right.$ ): $\delta 27.14$ (s, $\mathrm{CH}$ of i-Bu); 29.32 (s, $\mathrm{CH}_{3}$ of i-Bu); 33.94 (s, $\mathrm{CH}_{3}$ of t-BuO); 42.28 (s, $\mathrm{CH}_{3}$ of PMDETA); 46.26 (s, $\mathrm{CH}_{3}$ of PMDETA); 56.57 (s, $\mathrm{CH}_{2}$ of PMDETA); 56.74 (s, $\mathrm{CH}_{2}$ of PMDETA); 67.42 (s, C of t-BuO) ppm. ${ }^{7} \mathrm{Li} \mathrm{NMR}\left(155.5 \mathrm{MHz}, \mathrm{C}_{6} \mathrm{D}_{6}, 300 \mathrm{~K}\right.$ ): $\delta-0.228$ (s) ppm.

Synthesis of $\left[(\mathrm{i}-\mathrm{Bu})_{2} \mathrm{Al}(\mathrm{OBu}-\mathrm{t})_{2} \mathrm{Na}\right.$.TMEDA], 4: To a solution of NaHMDS $(0.365 \mathrm{~g} ; 2 \mathrm{mmol})$ in toluene $(5 \mathrm{ml})$ was added $\mathrm{Al}(\mathrm{i}-\mathrm{Bu})_{3}(1 \mathrm{M} /$ hexane; $2 \mathrm{ml}$; $2 \mathrm{mmol}$ ) and this was stirred at room temperature for 1 hour. To this, t$\mathrm{BuOH}$ was added $(0.375 \mathrm{ml} ; 4 \mathrm{mmol})$ and this transparent, colourless solution was allowed to stir at room temperature overnight. After this, all of the solvent was removed in vacuo leaving a colourless but viscous oil. This was resuspended in hexane $(2 \mathrm{ml})$ and TMEDA was added to the white suspension $(0.3 \mathrm{ml} ; 2 \mathrm{mmol})$. The transparent solution was stored at $-30{ }^{\circ} \mathrm{C}$ and a crop of colourless block crystals were present after several hours; these were isolated by filtration $\left(0.272 \mathrm{~g} ; 0.64 \mathrm{mmol} ; 32 \%\right.$ yield). ${ }^{1} \mathrm{H}$ NMR (400.1 MHz, $\left.\mathrm{C}_{6} \mathrm{D}_{6}, 300 \mathrm{~K}\right): \delta 0.393$ (d, J = 6.99 Hz, 4H, $\mathrm{CH}_{2}$ of i-Bu); 1.393 (s, $18 \mathrm{H}, \mathrm{CH}_{3}$ of t-BuO); 1.427 (d, J = 6.51 Hz, $12 \mathrm{H}, \mathrm{CH}_{3}$ of i-Bu); 1.613 (s, $4 \mathrm{H}, \mathrm{CH}_{2}$ of TMEDA); 1.766 (s, 12H, $\mathrm{CH}_{3}$ of TMEDA); 2.376 (nonet, $\mathrm{J}=$ $6.56 \mathrm{~Hz}, 2 \mathrm{H}, \mathrm{CH}$ of i-Bu) ppm. ${ }^{13} \mathrm{C}\left\{{ }^{1} \mathrm{H}\right\}$ NMR $\left(100.6 \mathrm{MHz}, \mathrm{C}_{6} \mathrm{D}_{6}, 300 \mathrm{~K}\right): \delta$ 27.55 (s, CH of i-Bu); 29.35 (s, $\mathrm{CH}_{3}$ of i-Bu); 34.13 (s, $\mathrm{CH}_{3}$ of t-BuO); 45.26 (s, $\mathrm{CH}_{3}$ of TMEDA); 56.37 (s, $\mathrm{CH}_{2}$ of TMEDA); 66.47 (s, $\mathrm{C}$ of t-BuO) ppm. 
Synthesis of [(i-Bu) ${ }_{2} \mathrm{Al}(\mathrm{OBu}-\mathrm{t})_{2} \mathrm{Na}$.PMDETA], 5: To a solution of NaHMDS $(0.365 \mathrm{~g} ; 2 \mathrm{mmol})$ in toluene $(5 \mathrm{ml})$ was added $\mathrm{Al}(\mathrm{i}-\mathrm{Bu})_{3}(1 \mathrm{M} /$ hexane; $2 \mathrm{ml}$; $2 \mathrm{mmol}$ ) and this was stirred at room temperature for 1 hour. To this, $\mathrm{t}$ $\mathrm{BuOH}$ was added $(0.375 \mathrm{ml} ; 4 \mathrm{mmol})$ and this transparent, colourless solution was allowed to stir at room temperature overnight. After this, all of the solvent was removed in vacuo leaving a colourless but viscous oil. This was re-suspended in hexane $(2 \mathrm{ml})$ followed by the addition of PMDETA $(0.46 \mathrm{ml} ; 2.2 \mathrm{mmol})$. The transparent, colourless solution was stored at $30{ }^{\circ} \mathrm{C}$ and a crop of colourless block crystals were present after several hours; these were isolated by filtration $(0.46 \mathrm{~g} ; 0.95 \mathrm{mmol} ; 48 \%$ yield $) .{ }^{1} \mathrm{H}$ NMR (400.1 MHz, $\left.\mathrm{C}_{6} \mathrm{D}_{6}, 300 \mathrm{~K}\right): \delta 0.332\left(\mathrm{~m}, 4 \mathrm{H}, \mathrm{CH}_{2}\right.$ of $\left.\mathrm{i}-\mathrm{Bu}\right) ; 1.412(\mathrm{~m}$, $12 \mathrm{H}, \mathrm{CH}_{3}$ of $\left.\mathrm{i}-\mathrm{Bu}\right) ; 1.449\left(\mathrm{~s}, 18 \mathrm{H}, \mathrm{CH}_{3}\right.$ of t-BuO); $1.816\left(\mathrm{~m}, 11 \mathrm{H}, \mathrm{CH}_{2}\right.$ and $\mathrm{CH}_{3}$ of PMDETA); 1.995 (s, 12H, $\mathrm{CH}_{3}$ of PMDETA); $2.379(\mathrm{~m}, 2 \mathrm{H}, \mathrm{CH}$ of i-Bu) ppm. ${ }^{13} \mathrm{C}\left\{{ }^{1} \mathrm{H}\right\}$ NMR $\left(100.6 \mathrm{MHz}, \mathrm{C}_{6} \mathrm{D}_{6}, 300 \mathrm{~K}\right): \delta 27.39$ (s, $\mathrm{CH}$ of i$\mathrm{Bu}$ ); 29.54 (s, $\mathrm{CH}_{3}$ of $\mathrm{i}-\mathrm{Bu}$ ); 34.32 (s, $\mathrm{CH}_{3}$ of t-BuO); 43.50 (s, $\mathrm{CH}_{3}$ of PMDETA); 45.70 (s, $\mathrm{CH}_{3}$ of PMDETA); 55.60 (s, $\mathrm{CH}_{2}$ of PMDETA); 57.27 (s, $\mathrm{CH}_{2}$ of PMDETA); 66.60 (s, C of t-BuO) ppm.

Synthesis of $\left[(\mathrm{i}-\mathrm{Bu})_{2} \mathrm{Al}(\mathrm{OBu}-\mathrm{t})_{2} \mathrm{~K}\right.$.PMDETA], 6: To a solution of KHMDS $(0.199 \mathrm{~g} ; 1 \mathrm{mmol})$ in hexane $(5 \mathrm{ml})$ was added $\mathrm{Al}(\mathrm{i}-\mathrm{Bu})_{3}(1 \mathrm{M} /$ hexane; $1 \mathrm{ml}$; $1 \mathrm{mmol}$ ) and this was stirred at room temperature for 1 hour. To this, $\mathrm{t}$ $\mathrm{BuOH}$ was added $(0.187 \mathrm{ml} ; 2 \mathrm{mmol})$ and the transparent, colourless solution was allowed to stir at room temperature overnight. After this, all of the solvent was removed in vacuo leaving a colourless but viscous oil. This was re-suspended in hexane $(2 \mathrm{ml})$ and PMDETA was added to the white suspension $(0.25 \mathrm{ml} ; 1.2 \mathrm{mmol})$; the now transparent, colourless solution was stored at $-30^{\circ} \mathrm{C}$ and a crop of colourless crystals were present after several hours. The crystals were isolated by filtration $(0.169 \mathrm{~g} ; 0.34 \mathrm{mmol}$; $34 \%$ yield). ${ }^{1} \mathrm{H}$ NMR $\left(400.1 \mathrm{MHz}, \mathrm{C}_{6} \mathrm{D}_{6}, 300 \mathrm{~K}\right): \delta 0.388\left(\mathrm{~m}, 4 \mathrm{H}, \mathrm{CH}_{2}\right.$ of $\mathrm{i}-$ $\mathrm{Bu}) ; 1.453\left(\mathrm{~s}, 18 \mathrm{H}, \mathrm{CH}_{3}\right.$ of t-BuO); $1.467\left(\mathrm{~m}, 12 \mathrm{H}, \mathrm{CH}_{3}\right.$ of $\left.\mathrm{i}-\mathrm{Bu}\right) ; 1.780(\mathrm{~m}$, $3 \mathrm{H}, \mathrm{CH}_{3}$ of PMDETA); $1.863\left(\mathrm{~m}, 8 \mathrm{H}, \mathrm{CH}_{2}\right.$ of PMDETA); $1.918\left(\mathrm{~s}, 12 \mathrm{H}, \mathrm{CH}_{3}\right.$ of PMDETA); 2.421 (m, 2H, CH of i-Bu) ppm. ${ }^{13} \mathrm{C}\left\{{ }^{1} \mathrm{H}\right\} \mathrm{NMR}(100.6 \mathrm{MHz}$, $\mathrm{C}_{6} \mathrm{D}_{6}, 300 \mathrm{~K}$ ): $\delta 27.73$ (s, $\mathrm{CH}$ of i-Bu); 29.54 (s, $\mathrm{CH}_{3}$ of i-Bu); 34.29 (s, $\mathrm{CH}_{3}$ of t-BuO); 41.48 (s, $\mathrm{CH}_{3}$ of PMDETA); 44.96 (s, $\mathrm{CH}_{3}$ of PMDETA); 55.41 (s, $\mathrm{CH}_{2}$ of PMDETA); 56.79 (s, $\mathrm{CH}_{2}$ of PMDETA); 66.48 (s, C of t-BuO) ppm.

Synthesis of [Al(dipp)3.THF], 7: To a solution of 2,6-diisopropylphenol (1.1 $\mathrm{ml} ; 6 \mathrm{mmol})$ in hexane $(10 \mathrm{ml})$ was added $\mathrm{Al}(\mathrm{Me})_{3}(2 \mathrm{M} / \mathrm{heptane} ; 1 \mathrm{ml} ; 2$ $\mathrm{mmol})$. The solution immediately turned dark green in colour and was left to stir at room temperature for 30 minutes, after which THF was added $(0.96 \mathrm{ml} ; 12 \mathrm{mmol})$ and this turned the solution pale yellow in colour. This was stirred at room temperature overnight. A pale pink suspension was present after this and all of the solvent was removed in vacuo leaving a pale green solid residue. Hexane $(4 \mathrm{ml})$ and toluene $(12 \mathrm{ml})$ were added to obtain a transparent, dark green solution and this was stored at $-30^{\circ} \mathrm{C}$; a crop of pale pink crystals were present after several days and these were isolated by filtration $\left(0.78 \mathrm{~g} ; 1.24 \mathrm{mmol} ; 62 \%\right.$ yield). ${ }^{1} \mathrm{H}$ NMR $(400.1 \mathrm{MHz}$, $\left.\mathrm{C}_{6} \mathrm{D}_{6}, 300 \mathrm{~K}\right): \delta 1.007\left(\mathrm{~m}, 4 \mathrm{H}, \mathrm{CH}_{2}\right.$ of THF); $1.221(\mathrm{~d}, \mathrm{~J}=6.82 \mathrm{~Hz}, 36 \mathrm{H}$, $\mathrm{CH}_{3}$ of i-Pr); 3.573 (septet, $\mathrm{J}=6.67 \mathrm{~Hz}, 6 \mathrm{H}, \mathrm{CH}$ of i-Pr); $3.901\left(\mathrm{~m}, 4 \mathrm{H}, \mathrm{CH}_{2}\right.$ of THF); 6.970 (t, J = $7.60 \mathrm{~Hz}, 3 \mathrm{H}$, para-CH of dipp); 7.127 (d, J $=7.68 \mathrm{~Hz}$, $6 \mathrm{H}$, meta-CH of dipp) ppm. ${ }^{13} \mathrm{C}\left\{{ }^{1} \mathrm{H}\right\}$ NMR $\left(100.6 \mathrm{MHz}, \mathrm{C}_{6} \mathrm{D}_{6}, 300 \mathrm{~K}\right): \delta$ 23.16 (s, $\mathrm{CH}_{3}$ of i-Pr); 24.05 (s, $\mathrm{CH}_{2}$ of THF); 26.29 (s, $\mathrm{CH}$ of i-Pr); 72.33 (s, $\mathrm{CH}_{2}$ of THF); 119.24 (s, para-CH of dipp); 122.73 (s, meta-CH of dipp); 136.64 (s, ortho-C of dipp); 151.34 (s, CO of dipp) ppm.

\section{Acknowledgements}

M.T.W. wishes to thank the University of Strathclyde for sponsoring his $\mathrm{PhD}$ studentship through the award of a Research Excellence Award (REA). Dr Stuart Robertson is also thanked for drawing the ToC figure.

Full crystallographic details of the mentioned compounds in .cif format are available from the CCDC (1999145 - 1999151).
Keywords: Alkali Metals • Aluminium • Ate Compounds • Heterobimetallics • Solid-state Structures

\section{Orcid}

A. R. Kennedy 0000-0003-3652-6015

R. E. Mulvey 0000-0002-1015-2564

[1] K. Ziegler, in Advances in Organometallic Chemistry, ed. R. West F. G. A. Stone, Academic Press, 1968, vol. 6, pp. 1-16.

[2] P. A. Chaloner, in The Chemistry of the Metal - Carbon Bond, ed. F. R. Hartley, Wiley, 1987, vol. 4, ch. 4, pp. 411-467.

[3] A. Salzer, C. Elschenbroich, in Organometallics: A Concise Introduction, ed. B. G. Teubner, Wiley VCH, 1992, ch. 7.2, pp. 75 85

[4] M. Witt, H. W. Roesky, Curr. Sci., 2000, 78, 410-430.

[5] D. A. Atwood, A. Mitra, in Comprehensive Organometallic Chemistry III, ed. R. H. Crabtree, D. M. P. Mingos, Elsevier, 2007, vol. 3, ch. 3.06, pp. 265-285

[6] C. Fliedel, S. Dagorne, in Modern Organoaluminum Reagents, ed. S. D. S. Woodward, Springer, 2012, vol. 41, pp. 125-171.

[7] M. R. Mason, in Encyclopedia of Inorganic and Bioinorganic Chemistry, Wiley, 2016

[8] J. Li, Y. Liu, X. Ma, Z. Yang, H. W. Roesky, Coord. Chem. Rev., 2018, 374, 387-415

[9] T. Saito, H. Minami, C. Wang, M. Uchiyama, Angew. Chem. Int. Ed, 2015, 54, 4665-4668.

[10] E. Holzkamp, K. Ziegler, H. Breil, H. Martin, Angew. Chem. Int. Ed, 1955, 16, 426.

G. W. Parshall, F. N. Tebbe, G. S. Reddy, J. Am. Chem. Soc., 1978 100, 3611-3613.

[12] P.-A. R. Breuil, A. Boudier, L. Magna, H. Olivier-Bourbigou, P. Braunstein, Dalton Trans., 2015, 44, 12995-12998.

[13] A. Earnshaw, N. N. Greenwood, Chemistry of the Elements, Butterworth-Heinemann, 2nd edn, 1997.

[14] X. Ma, W. Li, M. G. Walawalkar, Z. Yang, H. W. Roesky, Coord Chem. Rev., 2017, 350, 14-29.

[15] S. Sinhababu, M. K. Sharma, G. Mukherjee, G. Rajaraman, S Nagendran, Dalton Trans., 2017, 46, 7672-7676.

[16] A. J. P. White, C. Bakewell, M. R. Crimmin, Angew. Chem. Int. Ed, 2018, 57,6638-6642.

[17] X. Ma, Q. Shen, W. Li, W. Liu, Y. Ding, Z. Yang, H. W. Roesky, Chem. Eur. J., 2019, 25, 11918-11923.

[18] N. Gupta, A. Dogra, ChemistrySelect, 2019, 4, 10452-10465. M. Bhandari, S. Rawat, B. Prashanth, S. Singh, Chem. Cat. Chem., 2020, 12, 1-6.

A. D. Sadow, U. Kanbur, Chem. Eur. J., 2020, 26, 1-16.

M. Uzelac, R. E. Mulvey, S. D. Robertson, Chem. Rev., 2019, 119 8332-8405.

[22] S. A. Orr, V. A. Pollard, R. McLellan, A. R. Kennedy, E. Hevia, R. E. Mulvey, Chem. Commun., 2018, 54, 1233-1236.

[23] M. Á. Fuentes, V. A. Pollard, A. R. Kennedy, R. McLellan, R. E. Mulvey, Angew. Chem. Int. Ed, 2018, 57, 10651-10655.

[24] A. Young, V. A. Pollard, R. McLellan, A. R. Kennedy, T. Tuttle, R. E. Mulvey, Angew. Chem. Int. Ed., 2019, 58, 12291-12296.

[25] M. Uzelac, R. McLellan, A. R. Kennedy, R. E. Mulvey, E. Hevia, Angew. Chem. Int. Ed., 2017, 56, 9566-9570.

[26] M. Uzelac, R. E. Mulvey, Chem. Eur. J., 2018, 24, 7786-7793.

[27] E. Hevia, R. E. Mulvey, A. R. Kennedy, D. R. Armstrong, J. M. GilNegrete, L. J. Bole, M. Uzelac, R. McLellan, Synthesis, 2019, 51 1207-1215.

[28] M. Schlosser, J. Organomet. Chem., 1967, 8, 9-16.

M. Schlosser, Pure \& Appl. Chem., 1988, 60, 1627-1634.

M. Janata, L. Lochmann, Cent. Eur. J. Chem., 2014, 12, 537-548. M. Kaiser, P. Benrath, T. Limbach, M. Mondeshki, J. Klett, Angew. Chem. Int. Ed, 2016, 55, 10886-10889.

S. Kimpel, B. Jennewein, D. Thalheim, J. Klett, Chem. Eur. J. , 2018, 24, 7605-7609.

S. Kopf, A. J. Plajer, A. L. Colebatch, A. D. Bond, D. S. Wright, R García-Rodríguez, Dalton Trans., 2019, 48, 5692-5697.

R. F. Hernández-Campos, J. García-Ríos, F. Rascón-Cruz, V. A Moreno-Martínez, R. Huerta-Lavorie, M.-A. Velázquez-Carmona, R. Cea-Olivares, D. Martínez-Otero, V. Jancik, RSC. Adv., 2015, 5, 99722-99731.

[35] T. Muñoz, M. Palenzuela, J. F. Vega, A. Gutiérrez-Rodríguez, T. Cuenca, M. E. G. Mosquera, Dalton Trans., 2019, 48, 6435-6444.

[36] D. A. Atwood, M. S. Hill, Main Group Chemistry, 1998, 2, 285-292.

[37] J. C. Gordon, G. G. Giesbrecht, D. L. Clark, B. L. Scott, J. G. Watkin K. J. Young, Inorg. Chem., 2002, 41, 6372-6379.

[38] M. Westerhausen, Coord. Chem. Rev., 1998, 176, 157-210.

[39] P. Power, M. Lappert, A. Protchenko, A. Seeber, Metal Amide Chemistry, Wiley, 2009 
[40] S. D. Robertson, R. E. Mulvey, Angew. Chem. Int. Ed, 2013, 52, 11470-11487.

[41] M. P. Coles, Coord. Chem. Rev., 2015, 297-298, 2-39.

[42] H. Görls, P. Schüler, M. Westerhausen, S. Krieck, Dalton Trans. 2019, 48, 8966-8975.

[43] A. Jacobi von Wangelin, P. Ghosh, Org. Chem. Front., 2020, 7, 960966. Krieck, M. Westerhausen, Chem. Eur. J., 2020, In print.

P. Jutzi, A. H. Cowley, F. X. Kohl, J. G. Lasch, N. C. Norman, E. Schluter, Angew. Chem. Int. Ed, 1984, 23, 616-617.

M. G. Davidson, D. M. Cousins, D. García-Vivó, M. F. Mahon Dalton Trans., 2010, 39, 8203-8209.

[47] S. D. Bull, P. C. Andrews, M. Koutsaplis, New. J. Chem., 2010, 34, 1678-1691.

[48] A. Stasch, C. P. Sindlinger, Dalton Trans., 2014, 43, 14334-14345.

[49] F. H. Allen, Acta. Cryst., 2002, B58.

[50] D. Stalke, T. Stey, in The Chemistry of Organolithium Compounds, ed. I. M. Z. Rappoport, John Wiley \& Sons, 2004, pp. 47-120.

[51] P. v. R. Schleyer, C. Schade, Adv. Organomet. Chem., 1987, 27, 169-278.

[52] E. Weiss, Angew. Chem. Int. Ed, 1993, 32, 1501-1523.

[53] W. Tornau, E. G. Hoffmann, Angew. Chem., 1961, 73, 578

[54] W. Tornau, E. G. Hoffmann, United States Pat., 1964. DE 1162369.

[55] F. Olbrich, H. Nekola, U. Behrens, Z. Anorg. Allg. Chem., 2002, 628 2067-2070.

[56] R. Nassar, J. F. Allan, E. Specht, A. Beatty, N. Calin, K. W. Henderson, J. Am. Chem. Soc., 2004, 126, 484-485.

[57] R. N. R. Broomhall-Dillard, W. J. Evans, J. W. Ziller, Organometallics, 1996, 15, 1351-1355. W. Clegg, D. R. Armstrong, A. M. Drummond, S. T. Liddle, R. E.

[59] Aulvey, J. Am. Chem. Soc., 2000, 122, 11117-11124. Chem., 2004, 630, 821-828.

[60] A. R. Kennedy, H. R. L. Barley, R. E. Mulvey, Acta. Cryst., 2005, 61 346-347.

[61] A. Company, S. Krackl, S. Enthaler, M. Driess, Chem. Cat. Chem., 2011, 3, 1186-1192.

[62] S. Fadlallah, L. Wang, C. Bellini, C. Orione, V. Dorcet, J.-F. Carpentier, Y. Sarazin, Organometallics, 2015, 34, 1321-1327.

[63] T. J. Boyle, W. J. Evans, J. W. Ziller, Polyhedron, 1992, 11, 1093 1097.

[64] W.-Y. Chen, A. G. Avent, C. Eaborn, I. B. Gorrell, P. B. Hitchcock, J. D. Smith, Organometallics, 1996, 15, 4343-4345.

[65] B. Neumüller, J. Pauls, Z. Anorg. Allg. Chem., 2000, 626, 270-279.

[66] A. Schlegel, H. Noth, M. Suter, J. Organomet. Chem., 2001, 621, 231-241.

[67] B. Neumüller, J. Pauls, Z. Anorg. Allg. Chem., 2001, 627, 21272132.

[68] P. Konig, M. Veith, A. Rammo, V. Huch, Angew. Chem. Int. Ed, 2005, 44, 5968-5971.

[69] H. R. Simmonds, R. J. Less, D. S. Wright, Dalton Trans., 2014, 43 5785-5792.

[70] N. Trapp, P. Henke, C. E. Anson, H. Schnockel, Angew. Chem. Int Ed, 2010, 122, 3214-3218.

[71] S. Inoue, C. Weetman, Chem. Cat. Chem., 2018, 10, 4213-4228.

[72] C. Weetman, P. Bag, S. Inoue, Angew. Chem. Int. Ed, 2018, 57, 14394-14413.

[73] M. Garçon, C. Bakewell, R. Y. Kong, L. O'Hare, A. J. P. White, M. Crimmin, ChemRxiv, 2019, Pre-Print.

[74] L. V. Interrante, A. G. Williams, Mat. Res. Soc. Symp. Proc., 1984 32, 151-156.

[75] J. W. Ziller, M. D. Healy, A. R. Barron, J. Am. Chem. Soc., 1990, 112, 2949-2954.

[76] CrysalisPro, Agilent Technologies Ltd, 2014, Yarnton, Oxfordshire

G. M. Sheldrick, Acta. Cryst., 2015, C71, 3-8.

[78] L. J. Farrugia, J. Appl. Cryst., 2012, 45, 849-854.

[79] R. I. Cooper, R. O. Gould, S. Parsons, D. J. Watkin, J. Appl. Cryst., 2002, 35, 168-174.

[80] D. R. Armstrong, E. Herd, D. V. Graham, E. Hevia, A. R. Kennedy, W. Clegg, L. Russo, Dalton Trans., 2008, 1323-1330. 


\section{Entry for the Table of Contents}
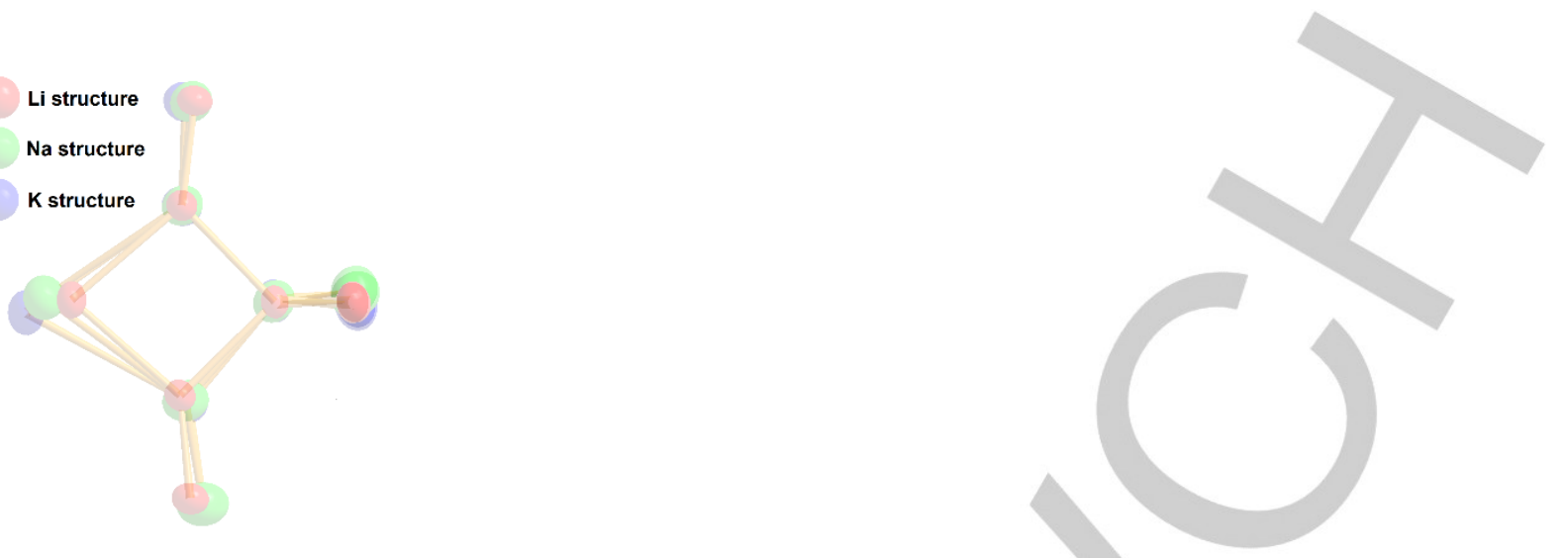

Formally co-complexes between monomeric forms of $(i-\mathrm{Bu})_{2} \mathrm{Al}(\mathrm{OBu}-t)$ and $t-\mathrm{BuO}(\mathrm{AM})$, a series of lithium, sodium, and potassium aluminates exhibit contacted ion pair structures, which irrespective of the alkali metal, share similar basic frameworks comprising heterodinuclear [AIO(AM)O] ring cores with four-coordinate $\mathrm{Al}$ and four or five coordinate $\mathrm{AM}$ centres, the latter completed by assorted donor ligands. 